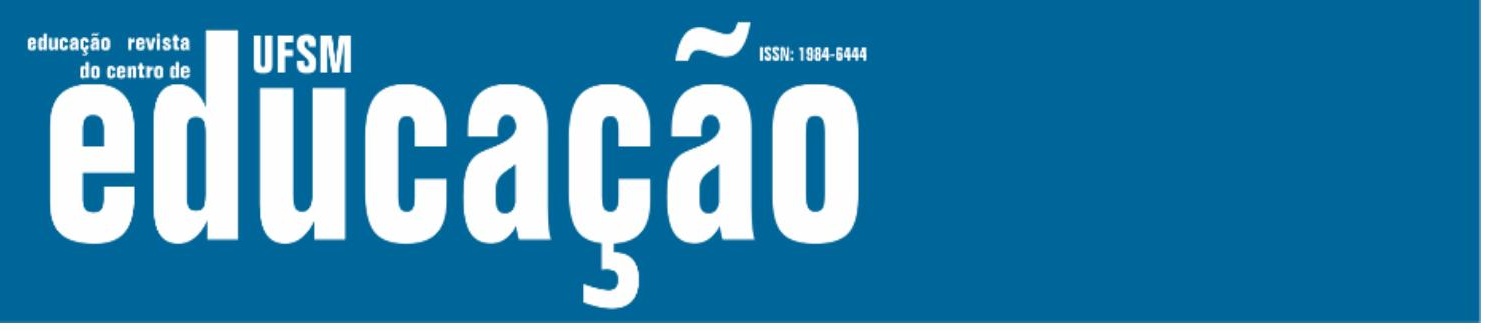

ISSN: 1984-6444 | http://dx.doi.org/10.5902/1984644441141

\title{
Elaboração de um material educativo para subsidiar a prática de professores de educação física no trabalho com alunos com perda auditiva
}

Development of educational material to subsidize the practice of physical education teachers in the working with hard of hearing students

\author{
Luciano Coelho Romera \\ Mestre pela Faculdade de Medicina de Marília. Marília, São Paulo, Brasil. \\ luichcoelho@gmail.com - https://orcid.org/0000-0001-8415-221X \\ Eliane Maria Carrit Delgado-Pinheiro \\ Professora Doutora na Universidade Estadual Paulista "Júlio de Mesquita Filho". Marília, São Paulo, \\ Brasil. \\ elia@terra.com.br - https://orcid.org/0000-0002-7589-2125
}

Flávia Rodrigues dos Santos

Mestranda na Universidade Estadual Paulista “Júlio de Mesquita Filho". Marília, São Paulo, Brasil.

flavia.unesp@outlook.com - https://orcid.org/0000-0002-5539-9501

Osni Lázaro Pinheiro

Professor Doutor na Faculdade de Medicina de Marília, Marília, São Paulo, Brasil.

osnilp@terra.com.br - https://orcid.org/0000-0002-6533-0428

Recebido em 15 de novembro de 2019

Aprovado em 18 de junho de 2020

Publicado em 31 de janeiro de 2021

\section{RESUMO}

No contexto educacional evidencia-se a necessidade de materiais educativos sobre a temática da perda auditiva que auxiliem professores de educação física em sua prática. O objetivo deste estudo foi elaborar e validar um material educativo para subsidiar a prática de professores de educação física nas atividades com alunos com perda auditiva. Foi construído um instrumento contendo assertivas sobre temas que poderiam ser abordados no material educativo. As assertivas foram acompanhadas por escala Likert. O item foi validado quando atingiu índice de concordância de $80 \%$. Os temas foram avaliados por juízes especialistas, das áreas de Fonoaudiologia $(n=4)$, Pedagogia $(n=2)$ e Educação Física $(n=2)$. Posteriormente foi elaborada uma versão preliminar do material validada pelos mesmos juízes e mais dois professores de educação física com experiência com alunos com perda auditiva. Nesta etapa a validação abordou aspectos do conteúdo, linguagem, ilustrações, layout, motivação e 


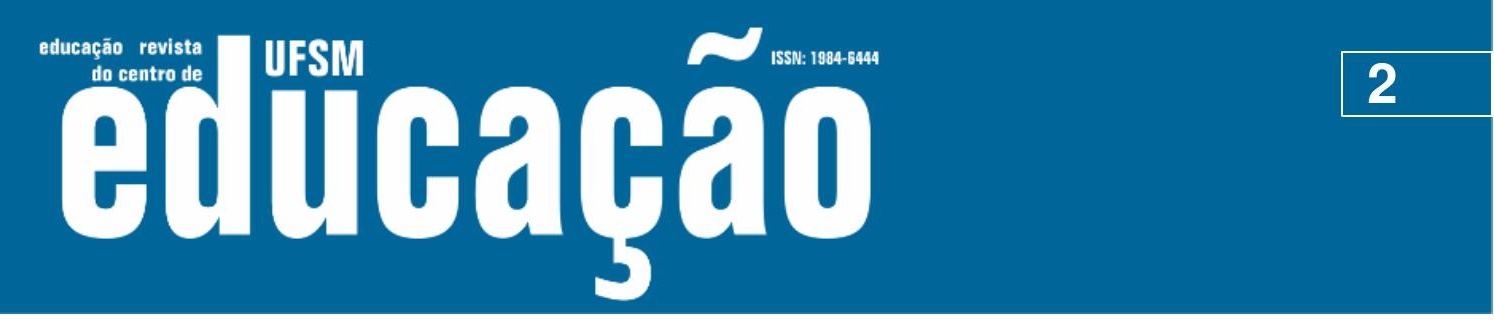

ISSN: 1984-6444 | http://dx.doi.org/10.5902/1984644441141

cultura, que deveriam atingir o índice de concordância de $80 \%$. Dentre os dez temas propostos, nove foram considerados pertinentes. $O$ item não validado referia-se ao uso de figuras com a Língua Brasileira de Sinais. Na segunda etapa do estudo, os únicos itens que não atingiram o índice de concordância mínimo referiam-se ao layout. As sugestões dos juízes relacionavam-se ao tamanho da letra e cores de fundo de algumas ilustrações. Foram realizadas as adequações sugeridas pelos juízes. 0 delineamento utilizado nesta pesquisa permitiu elaborar um material educativo validado com critérios metodológicos, contendo informações objetivas e ilustrações que poderão subsidiar professores de educação física na atuação com alunos com perda auditiva.

Palavras-chave: Educação física. Deficiência auditiva. Inclusão educacional.

\section{ABSTRACT}

In the educational context, there is a need for educational materials about the hearing loss to assist physical education teachers in their practice. This study aimed to develop and validate an educational material to subsidize the practice of physical education teachers in the activities with hard of hearing students. An instrument was built containing statements about the topics that could be addressed in the didactic material destined to the physical education teachers. The statements were followed by a Likert scale. The item was considered valid when it reached $80 \%$ index of agreement. The themes were evaluated by expert judges, from the fields of Speech Therapy $(n=4)$, Pedagogy $(n=2)$, and Physical Education $(n=2)$. After that, it was drafted a preliminary version of the material, which was validated by the same judges and another two physical education teachers with experience with hard of hearing students. At this stage, the validation approached aspects related to the matter, language, illustrations, layout, motivation, and culture, which should reach an $80 \%$ of the agreement. Within ten themes proposed, nine were considered relevant. The item that was not validated referred to the use of figures with the Brazilian sign language - Libras. In the second stage of the study, the only items which have not achieved the minimum index of the agreement were related to the layout. The judges' suggestions were pertaining to the size of the font and background colors of some illustrations. The adjustments suggested by the judges were implemented. The design used in this study allowed to elaborate and to validate an educational material based on methodological criteria, containing objective information and illustrations which will be able to subsidize the work of physical education teachers in the performance with students with hearing loss. Keywords: Physical education. Hearing impairment. Mainstreaming (Education). 


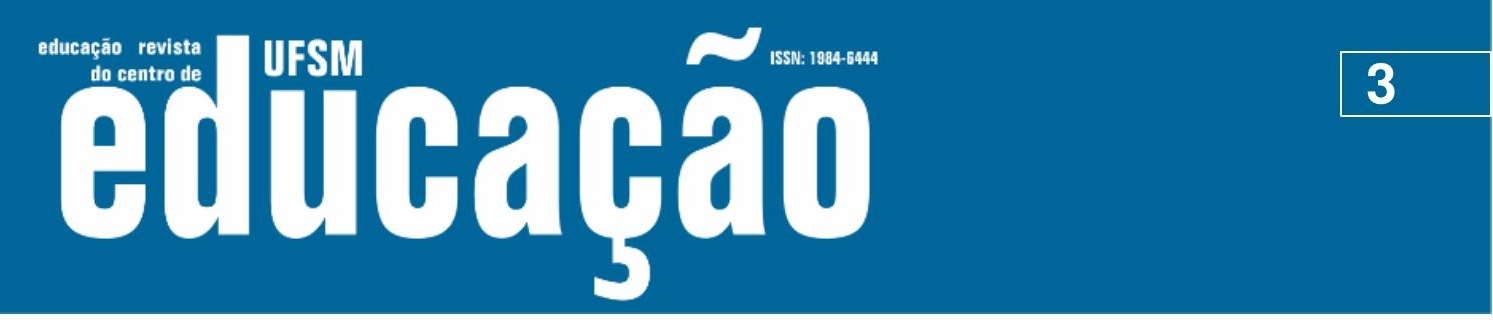

ISSN: 1984-6444 | http://dx.doi.org/10.5902/1984644441141

\section{Introdução}

A deficiência auditiva é caracterizada por uma privação sensorial que apresenta impacto direto no desenvolvimento da linguagem falada (OLIVEIRA; PENNA; LEMOS, 2015), causando repercussões nos diversos níveis de inserção do indivíduo, como o familiar, social, escolar e profissional.

A comunicação com o indivíduo que apresenta perda auditiva poderá se estabelecer por meio da audição, ou seja, com o uso da linguagem falada e também por meio da visão, utilizando a língua de sinais (PASSOS, 2014; PIMPERTON et al., 2017).

O impacto para o desenvolvimento comunicativo do indivíduo com perda auditiva que utiliza a linguagem falada está diretamente relacionado a fatores como 0 período da vida em que ocorreu o comprometimento da audição, o tipo e o grau da perda auditiva, o tempo de privação sensorial, a utilização adequada de dispositivos tecnológicos para o acesso aos sons da fala, a intervenção adequada e o envolvimento da família e da escola (BICAS; GUIJO; DELGADO-PINHEIRO, 2017; NOVAES et al., 2012).

Da mesma forma, na língua de sinais, a intervenção mais precoce, fará com que o usuário desenvolva maior fluência neste tipo de comunicação.

No Brasil é regulamentada a Língua Brasileira de Sinais (Libras), que foi instituída pela Lei oㅜ 10.436 (2002). A Libras é composta por parâmetros primários que envolvem as configurações das mãos, ponto de articulação e movimento, e parâmetros secundários, como expressões faciais, direcionalidade e orientação das palmas das mãos (PASSOS, 2014).

Em relação à escola é importante compreender que caso não haja um acompanhamento adequado de suas necessidades, o desempenho acadêmico do aluno poderá sofrer os impactos da deficiência auditiva (SENO, 2009).

No caso dos alunos que utilizam comunicação oral, deve-se dar atenção a aspectos como ruído, excesso de alunos em uma mesma classe, falta de conhecimento do professor sobre o seu aluno e sobre os dispositivos tecnológicos e 


\section{$\sim$

ISSN: 1984-6444 | http://dx.doi.org/10.5902/1984644441141

pergunta de pesquisa do presente estudo

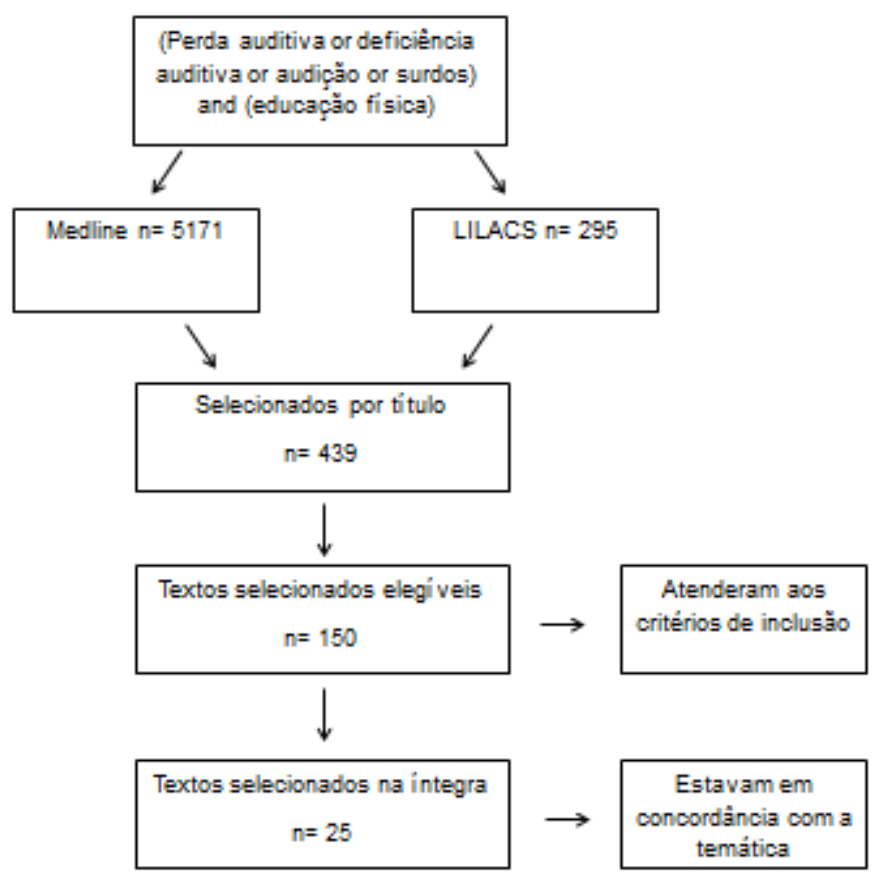

Fonte: Elaborada pelos autores.

Em seguida, foi construído um instrumento contendo assertivas sobre os temas que poderiam ser abordados no material educativo destinado para os professores de Educação Física que realizam atividades com alunos com perda auditiva.

Estas assertivas foram seguidas de uma escala do tipo Likert com quatro pontos: concordo totalmente, concordo, discordo e discordo totalmente. Cada uma das assertivas era seguida também de um campo aberto, no qual os participantes poderiam expressar livremente suas opiniões sobre o assunto.

As assertivas foram estruturadas em um formulário da plataforma eletrônica Google ${ }^{\circledR}$ e o link para acesso a esse formulário foi enviado para todos os juízes via email, de modo que as opiniões para a validação dos temas fossem emitidas anonimamente.

A partir das sugestões dos juízes foi elaborada uma versão inicial do material, a qual foi enviada a um ilustrador, para criação dos personagens, imagens e capa e ao diagramador para a confecção da arte visual. 


\section{U Hism

ISSN: 1984-6444 | http://dx.doi.org/10.5902/1984644441141

profissional na área de atuação entre 10 e 30 anos. Em relação à titulação, a maioria apresenta no mínimo o título de doutor (Quadro 1).

Quadro 1 - Caracterização dos profissionais que participaram na definição dos temas do material educativo (juízes 1 a 8) e na avaliação do material (juízes 1 a 10)

\begin{tabular}{|c|c|c|c|c|c|}
\hline Juíz & Formação & $\begin{array}{l}\text { idade } \\
\text { (anos) }\end{array}$ & Experiência (anos) & Titulação & Área de atuação \\
\hline J1 & $\begin{array}{l}\text { Educador } \\
\text { Físico }\end{array}$ & 52 & 30 & Pós-Doutorado & Educação Especial \\
\hline J2 & Pedagogo & 38 & 10 & Doutorado & $\begin{array}{c}\text { Educação. } \\
\text { Educação Especial. } \\
\text { Ensino de Libras. }\end{array}$ \\
\hline J3 & Fonoaudiólogo & 39 & 17 & Doutorado & Audiologia \\
\hline J4 & $\begin{array}{l}\text { Educador } \\
\text { Físico }\end{array}$ & 32 & 10 & Pós-Doutorado & $\begin{array}{l}\text { Educação Física e } \\
\text { Educação Especial }\end{array}$ \\
\hline J5 & Pedagogo & 52 & 30 & Doutorado & Educação \\
\hline J6 & Fonoaudiólogo & 51 & 30 & Doutorado & Audiologia Clínica \\
\hline J7 & Fonoaudiólogo & 48 & 25 & Doutorado & $\begin{array}{c}\text { Educação } \\
\text { Inclusiva/desmedica } \\
\text { lização da } \\
\text { educação }\end{array}$ \\
\hline J8 & Fonoaudiólogo & 45 & 20 & Pós-Doutorado & $\begin{array}{c}\text { Audiologia } \\
\text { Educacional }\end{array}$ \\
\hline J9 & $\begin{array}{l}\text { Educador } \\
\text { Físico }\end{array}$ & 56 & 20 & Graduação & $\begin{array}{l}\text { Educação Física } \\
\text { (Ensino } \\
\text { Fundamental e } \\
\text { Médio) }\end{array}$ \\
\hline J10 & $\begin{array}{l}\text { Educador } \\
\text { Físico }\end{array}$ & 50 & 11 & Graduação & $\begin{array}{l}\text { Educação Física, } \\
\text { Letras e Pedagogia } \\
\text { (Ensino } \\
\text { Fundamental e } \\
\text { Médio) }\end{array}$ \\
\hline
\end{tabular}

Fonte: Elaborado pelos autores.

A tabela 1 apresenta o índice de concordância dos juízes em relação aos temas inicialmente propostos para o material educativo.

Tabela 1 - Avaliações dos juízes (J1 a J8) em relação aos temas propostos para o material educativo 


\section{Tusm oltibapá \\ 3}

ISSN: 1984-6444 | http://dx.doi.org/10.5902/1984644441141

\begin{tabular}{|c|c|c|c|c|c|}
\hline ASSERTIVA & C & CT & D & DT & Concordância (\%) \\
\hline $\begin{array}{l}\text { 1) A cartilha deve contemplar o } \\
\text { conceito de deficiência auditiva. }\end{array}$ & 2 & 6 & 0 & 0 & 100 \\
\hline $\begin{array}{l}\text { 2) A cartilha deve informar sobre a } \\
\text { classificação da deficiência auditiva } \\
\text { de acordo com o tipo e grau de } \\
\text { perda e o impacto na comunicacão. }\end{array}$ & 2 & 6 & 0 & 0 & 100 \\
\hline $\begin{array}{l}\text { 3) A cartilha deve abordar sobre o } \\
\text { diagnóstico da deficiência auditiva }\end{array}$ & 3 & 4 & 1 & 0 & 87,5 \\
\hline $\begin{array}{l}\text { 4) A cartilha deve explicar sobre a } \\
\text { abordagem aurioral (estratégias de } \\
\text { comunicação para os deficientes } \\
\text { auditivos que utilizam a linguagem } \\
\text { falada) }\end{array}$ & 1 & 7 & 0 & 0 & 100 \\
\hline $\begin{array}{l}\text { 5) A cartilha deve descrever os } \\
\text { dispositivos tecnológicos } \\
\text { disponíveis para acesso aos sons da } \\
\text { fala (Aparelhos de Amplificação } \\
\text { Sonora Individual-AASI, Implante } \\
\text { Coclear-IC, Sistema de Frequência } \\
\text { Modulada - FM. }\end{array}$ & 1 & 7 & 0 & 0 & 100 \\
\hline $\begin{array}{l}\text { 6) A cartilha deve conter figuras } \\
\text { ilustrativas sobre os dispositivos } \\
\text { tecnológicos disponíveis para o } \\
\text { acesso aos sons da fala (AAASI, IC } \\
\text { e FM) e cuidados básicos com os } \\
\text { referidos dispositivos. }\end{array}$ & 2 & 6 & 0 & 0 & 100 \\
\hline $\begin{array}{l}\text { 7) A cartilha deve explicar sobre a } \\
\text { abordagem que utiliza a Língua } \\
\text { Brasileira de Sinais (Libras). }\end{array}$ & 3 & 4 & 1 & 0 & 87,5 \\
\hline $\begin{array}{l}\text { 8) A cartilha deve conter exemplos } \\
\text { de figuras com a Língua Brasileira } \\
\text { de Sinais. }\end{array}$ & 2 & 3 & 2 & 0 & 71,4 \\
\hline $\begin{array}{l}\text { 9) A cartilha deve conter estratégias } \\
\text { de comunicação que auxiliem os } \\
\text { alunos que utilizam Libras. }\end{array}$ & 3 & 5 & 0 & 0 & 100 \\
\hline
\end{tabular}

Fonte: Elaborada pelos autores.

Legenda: C: Concordo, CT: Concordo Totalmente, D: Discordo, DT: Discordo Totalmente.

Após a avaliação dos juízes, verificou-se que, dentre as dez assertivas que foram analisadas, sete apresentaram 100\% de concordância e duas obtiveram concordância de 87,5\%. Entretanto, a assertiva 8, relacionada a necessidade de o material educativo conter exemplos de figuras com a Língua Brasileira de Sinais, não atingiu a porcentagem mínima para a validação $(71,4 \%)$. Cabe destacar que um juiz 


\section{usm

ISSN: 1984-6444 | http://dx.doi.org/10.5902/1984644441141

Tabela 2 - Avaliação do material educativo realizada pelos juízes $(n=10)$

\begin{tabular}{|c|c|c|c|c|c|}
\hline ASSERTIVA & C & CT & D & DT & Concordância (\%) \\
\hline \multicolumn{6}{|l|}{ 1.Conteúdo } \\
\hline $\begin{array}{l}1.1 \text { O conteúdo está apropriado ao público } \\
\text { alvo (Professores de Educação Física de } \\
\text { alunos com perda auditiva) }\end{array}$ & 4 & 6 & - & - & 100 \\
\hline $\begin{array}{l}1.2 \text { A divisão dos títulos e subtítulos do } \\
\text { material são pertinentes }\end{array}$ & 3 & 7 & - & - & 100 \\
\hline $\begin{array}{l}1.3 \text { Os trechos-chave (trechos em destaque) } \\
\text { são pontos importantes e merecem destaque }\end{array}$ & 4 & 6 & - & - & 100 \\
\hline $\begin{array}{l}1.4 \text { O conteúdo é suficiente para atender as } \\
\text { necessidades do público alvo (Professores de } \\
\text { Educação Física de alunos com perda } \\
\text { auditiva) }\end{array}$ & 5 & 4 & 1 & - & 90 \\
\hline \multicolumn{6}{|l|}{ 2. Linguagem } \\
\hline $\begin{array}{l}2.1 \text { O estilo da redação é compatível com o } \\
\text { público alvo (Professores de Educação Física } \\
\text { de alunos com perda auditiva) }\end{array}$ & 4 & 6 & - & - & 100 \\
\hline 2.2 A escrita utilizada é atrativa & 5 & 4 & 1 & - & 90 \\
\hline 2.3 A linguagem é clara e objetiva & 5 & 5 & - & - & 100 \\
\hline \multicolumn{6}{|l|}{ 3. Ilustrações } \\
\hline $\begin{array}{l}\text { 3.1 As ilustrações utilizadas são pertinentes } \\
\text { com o conteúdo do material e esclarecem o } \\
\text { conteúdo }\end{array}$ & 4 & 6 & - & - & 100 \\
\hline $\begin{array}{l}\text { 3.2 As ilustrações são claras e transmitem } \\
\text { facilidade de compreensão }\end{array}$ & 5 & 5 & - & - & 100 \\
\hline $\begin{array}{l}\text { 3.3 As legendas das imagens são adequadas } \\
\text { e auxilia o leitor a compreender a imagem }\end{array}$ & 4 & 5 & 1 & - & 90 \\
\hline $\begin{array}{l}3.4 \text { A quantidade de ilustrações está } \\
\text { adequada para o conteúdo do material } \\
\text { educativo }\end{array}$ & 3 & 6 & 1 & - & 90 \\
\hline \multicolumn{6}{|l|}{ 4. Layout } \\
\hline 4.1 O tipo de letra utilizado facilita a leitura & 4 & 3 & 3 & - & 70 \\
\hline $\begin{array}{l}4.2 \text { As cores aplicadas ao texto são } \\
\text { pertinentes e facilitadoras para a leitura }\end{array}$ & 4 & 3 & 3 & - & 70 \\
\hline $\begin{array}{l}4.3 \text { A composição visual está atrativa e bem } \\
\text { organizada }\end{array}$ & 3 & 6 & 1 & - & 90 \\
\hline $\begin{array}{l}4.4 \text { O formato (tamanho) do material } \\
\text { educativo e o número de páginas estão } \\
\text { adequados }\end{array}$ & 5 & 5 & - & - & 100 \\
\hline 4.5 A disposição do texto está adequada & 5 & 4 & 1 & - & 90 \\
\hline $\begin{array}{l}4.6 \text { O tamanho das letras dos títulos, } \\
\text { subtítulos e textos estão adequados }\end{array}$ & 4 & 4 & 2 & - & 80 \\
\hline \multicolumn{6}{|l|}{ 5. Motivação } \\
\hline $\begin{array}{l}5.1 \text { O conteúdo está motivador e incentiva a } \\
\text { prosseguir com a leitura }\end{array}$ & 6 & 4 & - & - & 100 \\
\hline 5.2 O conteúdo despertou interesse no leitor & 4 & 6 & - & - & 100 \\
\hline
\end{tabular}




\section{Tusm

ISSN: 1984-6444 | http://dx.doi.org/10.5902/1984644441141

Continuação Tabela 2 - Avaliação do material educativo realizada pelos juízes $(\mathrm{n}=10)$

\begin{tabular}{|c|c|c|c|c|c|}
\hline $\begin{array}{l}5.3 \text { O conteúdo atende as dúvidas mais } \\
\text { comuns dos professores de Educação Física } \\
\text { de alunos com perda auditiva }\end{array}$ & 7 & 3 & - & - & 100 \\
\hline \multicolumn{6}{|l|}{ 6. Cultura } \\
\hline $\begin{array}{l}\text { 6.1 O texto está compatível com o público alvo } \\
\text { (Professores de Educação Física de alunos } \\
\text { com perda auditiva) atendendo aos diferentes } \\
\text { níveis de conhecimento }\end{array}$ & 4 & 6 & - & - & 100 \\
\hline
\end{tabular}

Fonte: Elaborada pelos autores.

Legenda: C: Concordo, CT: Concordo Totalmente, D: Discordo, DT: Discordo Totalmente.

Na tabela 2 observa-se que os únicos itens que não atingiram o índice utilizado para a validação foram referentes ao layout. Os resultados mostraram que o tipo de letra utilizada não estava facilitando a leitura e as cores aplicadas ao texto não eram pertinentes e facilitadoras da leitura. Ambos atingiram escores de $70 \%$.

As avaliações dos juízes realizadas nos campos abertos do instrumento também apontaram a necessidade de acertos no layout para algumas ilustrações específicas do material educativo. Os referidos apontamentos foram corrigidos para a versão final do material educativo. A formatação do texto foi centralizada, as cores de fundos dos quadros modificadas, bem como os tamanhos de letras.

De uma maneira geral os juízes elogiaram o material e um dos avaliadores (J3) considerou que o mesmo também poderia ser direcionado aos professores que desenvolvem as atividades físicas com alunos com perda auditiva, mesmo não tendo a formação específica de educador físico.

A situação mencionada por este especialista pode ocorrer, principalmente, na pré-escola, ou mesmo no ensino fundamental, dependendo principalmente do contexto do município (BRASIL, 1996).

Um dos juízes sugeriu enriquecer o material com informações sobre a combinação de jogadas e esquemas de tática no futebol, por meio do uso de Libras nas aulas de educação física, ampliando assim as possibilidades de inclusão. 


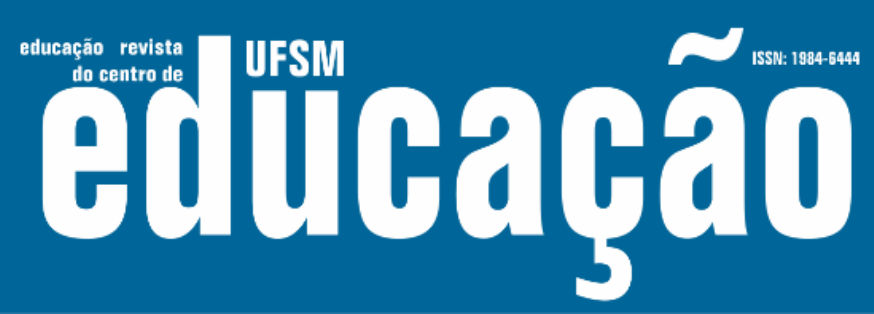

ISSN: 1984-6444 | http://dx.doi.org/10.5902/1984644441141

Quadro 2 - Representação ilustrativa da versão final do material e educativo

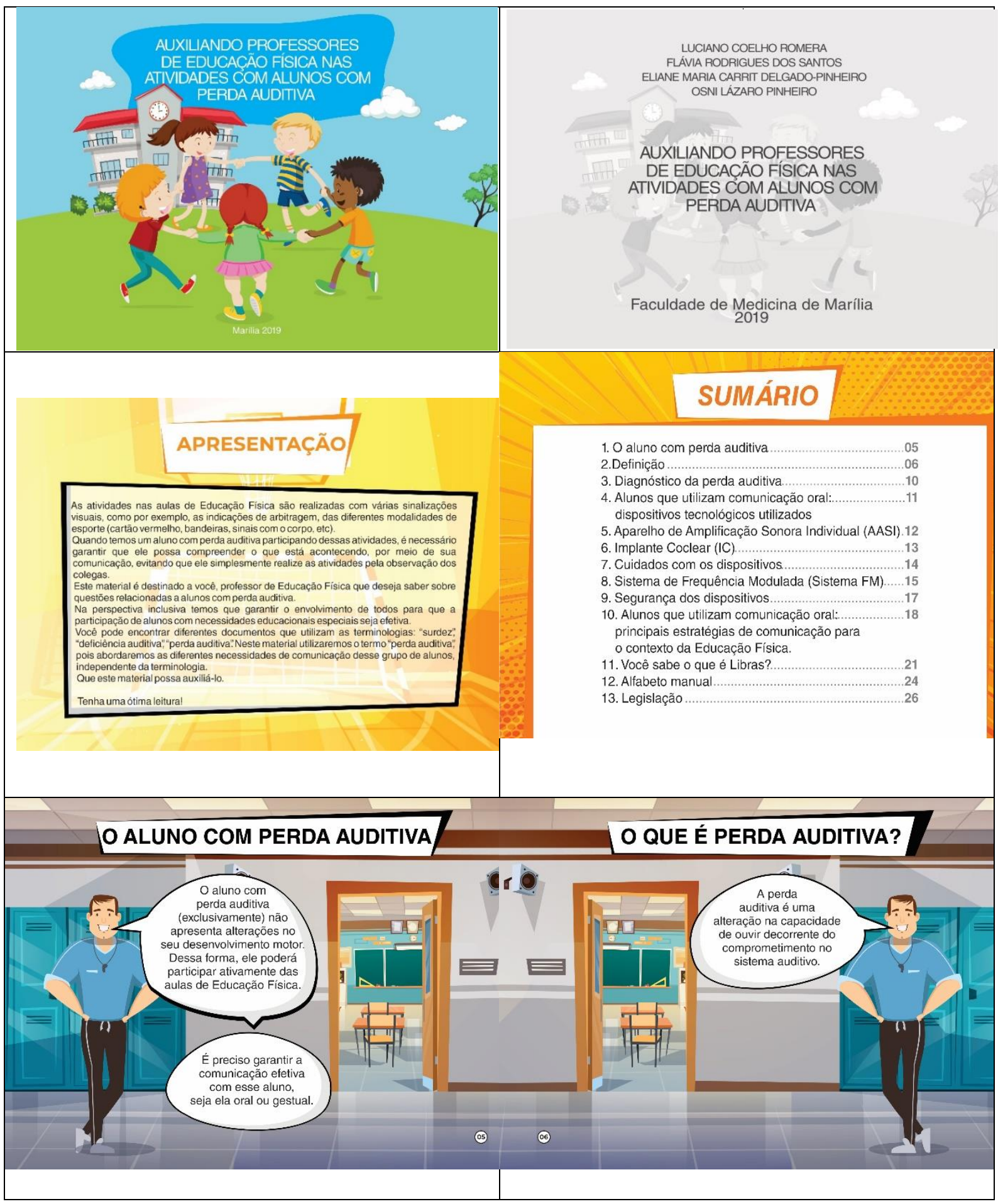

Educação | Santa Maria | v. 46 |2021

Disponível em: https://periodicos.ufsm.br/reveducacao 


\section{Eltînấó}

ISSN: 1984-6444 | http://dx.doi.org/10.5902/1984644441141

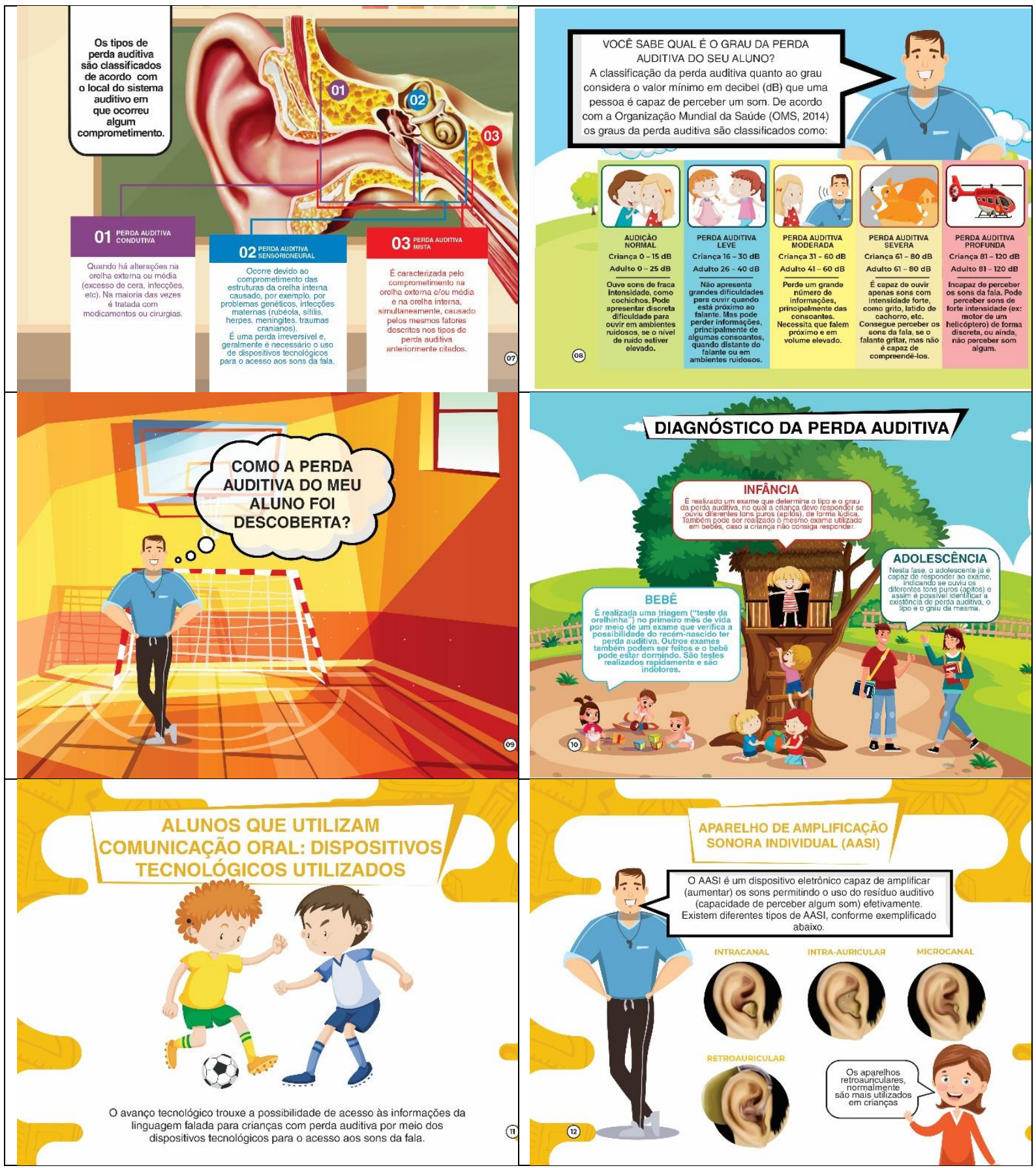

Educação | Santa Maria | v. 46 |2021

Disponível em: https://periodicos.ufsm.br/reveducacao 


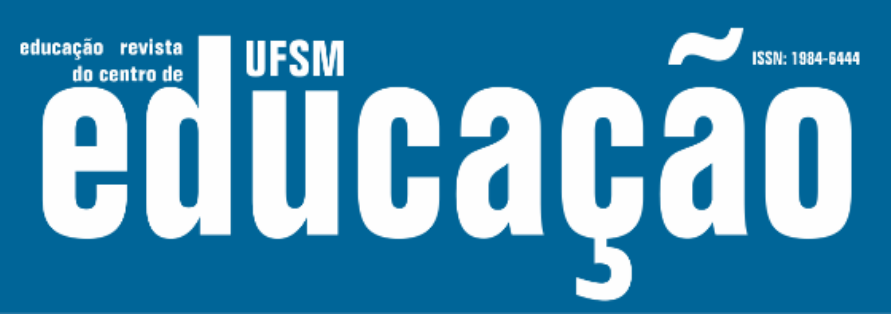

ISSN: 1984-6444 | http://dx.doi.org/10.5902/1984644441141

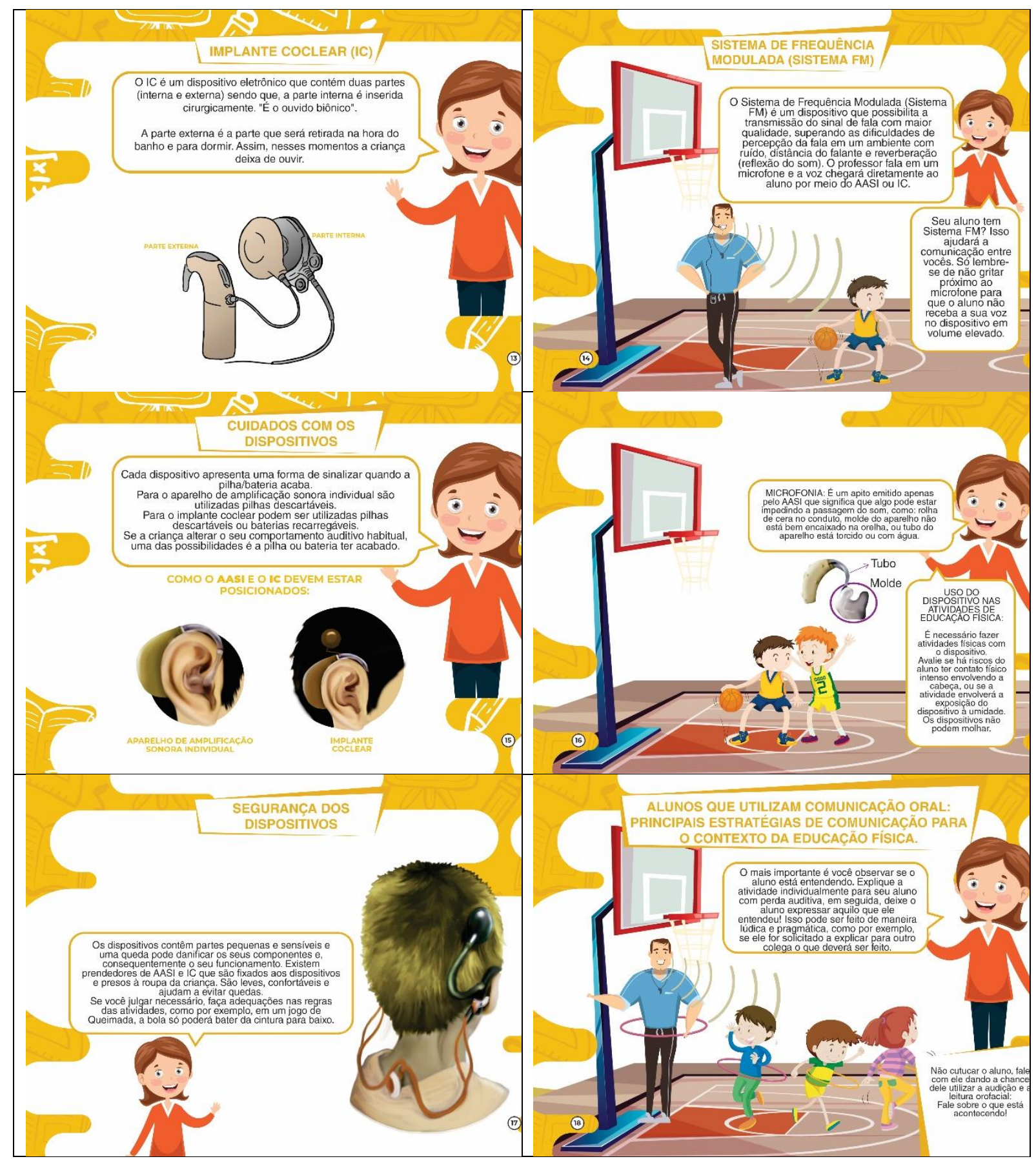

Educação | Santa Maria | v. 46 |2021

Disponível em: https://periodicos.ufsm.br/reveducacao 


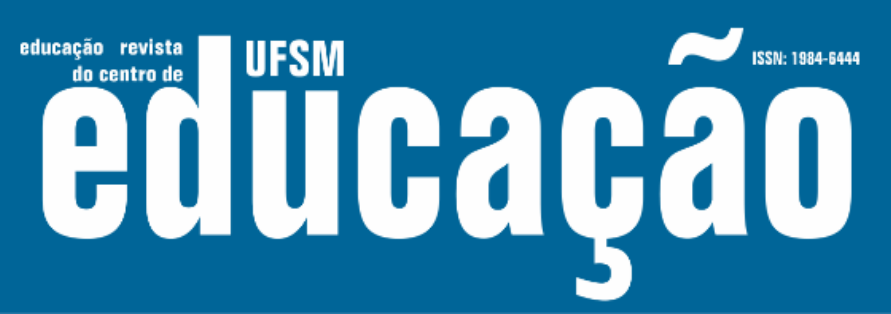

ISSN: 1984-6444 | http://dx.doi.org/10.5902/1984644441141

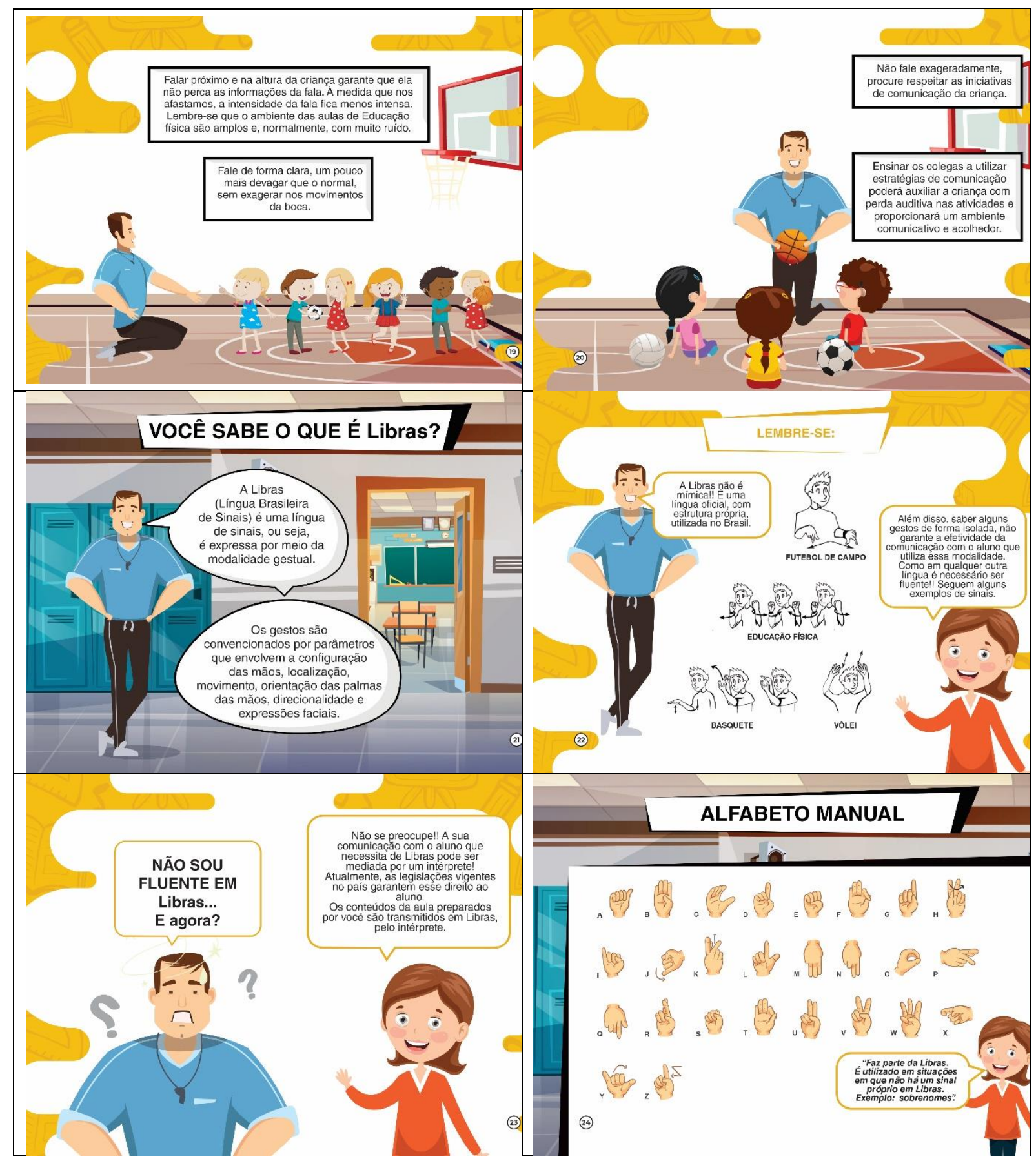

Educação | Santa Maria | v. 46 |2021

Disponível em: https://periodicos.ufsm.br/reveducacao 


\section{Autตaคูão}

ISSN: 1984-6444 | http://dx.doi.org/10.5902/1984644441141

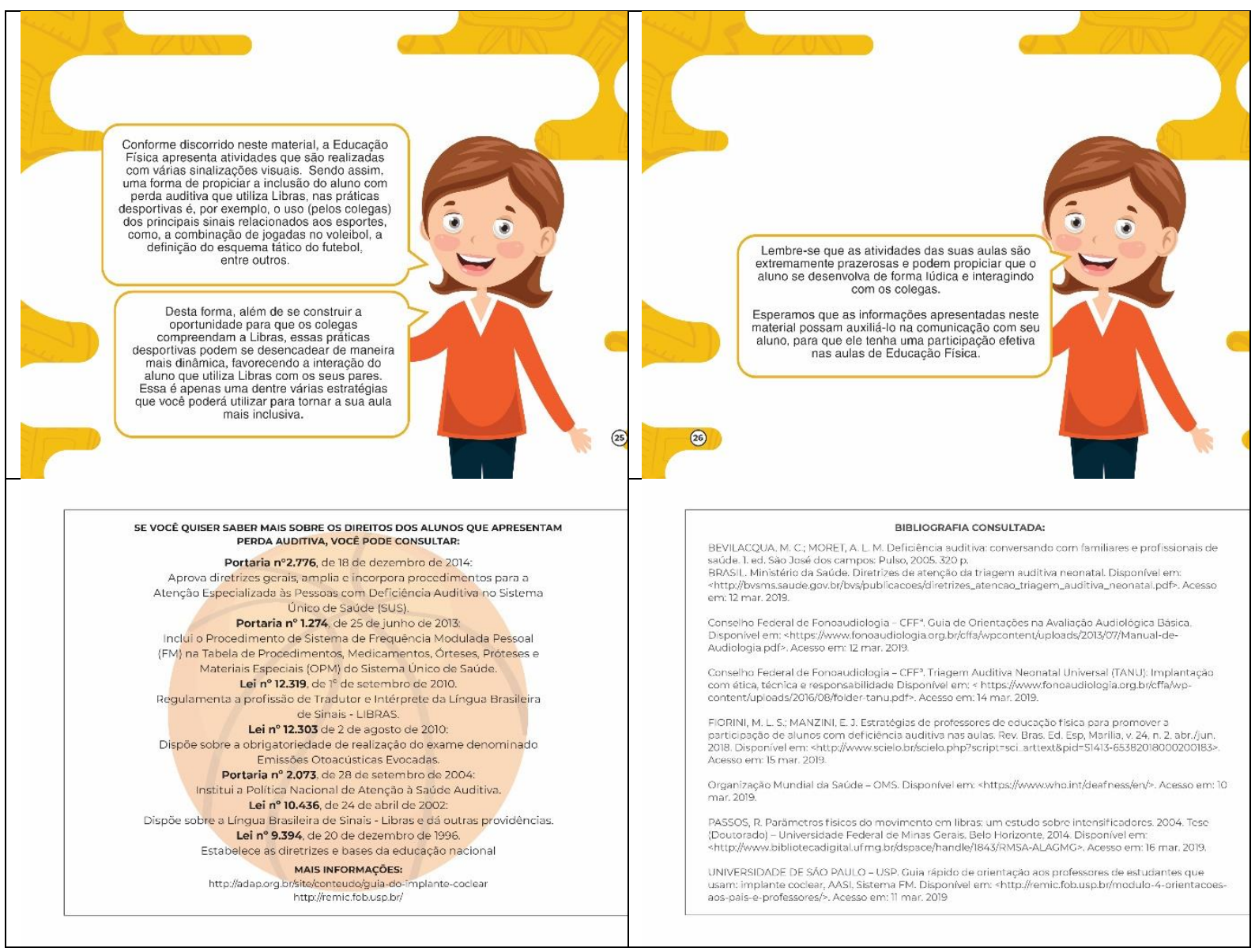

Fonte: Elaborado pelos autores.

\section{Considerações finais}

A educação física é uma disciplina que facilmente integra os alunos que frequentam suas aulas, porém a comunicação é um elemento essencial nesse processo. Desta forma, o professor de educação física, necessita de informações para atuar junto a alunos com perda auditiva.

O delineamento utilizado no presente estudo permitiu a construção de um material educativo validado a partir de critérios metodológicos. O produto final deste estudo contém informações objetivas e ilustrações que poderão subsidiar o trabalho de professores de educação física na atuação com alunos com perda auditiva.

A amplitude de atuação dos professores de educação física, que estão inseridos da pré-escola até o ensino médio, a repercussão destas atividades no 


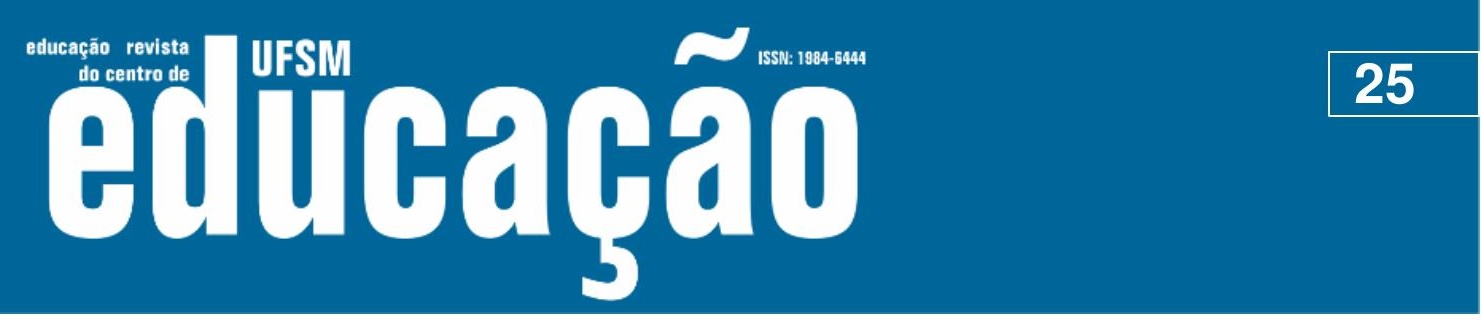

ISSN: 1984-6444 | http://dx.doi.org/10.5902/1984644441141

BRASIL. Casa Civil. Lei no 9.304 de 20 de dezembro de 1996. Brasília, DF, 1996.

BRASIL. Ministério da Educação. O tradutor e intérprete de língua brasileira de sinais e língua portuguesa. Brasília, DL, 2004.

BRASIL. Ministério da Saúde. Portaria no 2.776 de 18 de dezembro de 2014. Brasília, DF, 2014.

BRASIL. Ministério da Saúde. Portaria no 2.073 de 28 de setembro de 2004. Brasília, DF, 2004.

DAMÁZIO, Mirlene Ferreira Macedo. Atendimento educacional especializado. Paraná: Cromos. 2007.

DELGADO-PINHEIRO, Eliane Maria Carrit et al. Programa de acompanhamento fonoaudiológico de professores de alunos deficientes auditivos que utilizam a comunicação oral. Revista Distúrbios da Comunicação, São Paulo, v.21, n.1, 2009. Disponível em: https://revistas.pucsp.br/dic/article/view/6943. Acesso em: 21 jul. 2019.

DELGADO-PINHEIRO, Eliane Maria Carrit; OMOTE, Sadao. Teachers' knowledge about hearing loss and attitudes towards the inclusion. Revista CEFAC, São Paulo, v.12, n.4,abr. 2010. Disponível em: http://www.scielo.br/scielo.php?pid=S151618462010005000024\&script=sci_abstract. Acesso em: 23 jul. 2019.

FIORINI, Maria Luiza Salzani; MANZINI, Eduardo José. Strategies of Physical Education Teachers to Promote the Participation of Students with Hearing Impairment in Classrooms. Revista Brasileira de Educação Especial, Bauru, v.24, n.2, abr/jun. 2018. Disponível em: http://www.scielo.br/pdf/rbee/v24n2/en_1413-6538-rbee-24-020183.pdf. Acesso em: 22 jul. 2019.

MELO, Tatiana Mendes et al. Influence of signal processing strategy in auditory abilities. Brazilian Journal of Otorhinolaryngology, São Paulo, v.79, n.5, set/out. 2013. Disponível em: http://www.scielo.br/pdf/bjorl/v79n5/en_1808-8694-bjorl-79-050629.pdf. Acesso em: 6 ago. 2019.

MONTEIRO, Rosa; SILVA, Daniele Nunes Henrique; RATNER, Carl. Narrative of Brazilian Individuals after Deafness Diagnosis. Psicologia: Teoria e Pesquisa, Brasília, v.32, n.5, mar. 2017. Disponível em: http://www.scielo.br/pdf/ptp/v32nspe/en_1806-3446-ptp-32-spe-e32ne210.pdf.

Acesso em: 2 ago. 2019.

MUNARETTO, Lorimar Francisco; CORRÊA, Hamilton Luiz; CUNHA, Júlio Araújo Carneiro da. Um estudo sobre as características do método Delphi e de grupo focal, como técnicas na obtenção de dados em pesquisas exploratórias. Revista de Administração da UFSM, Santa Maria. v.6, n.1, jan/mar.2013. Disponível em: https://periodicos.ufsm.br/reaufsm/article/view/6243/pdf. Acesso em: 6 ago. 2019. 


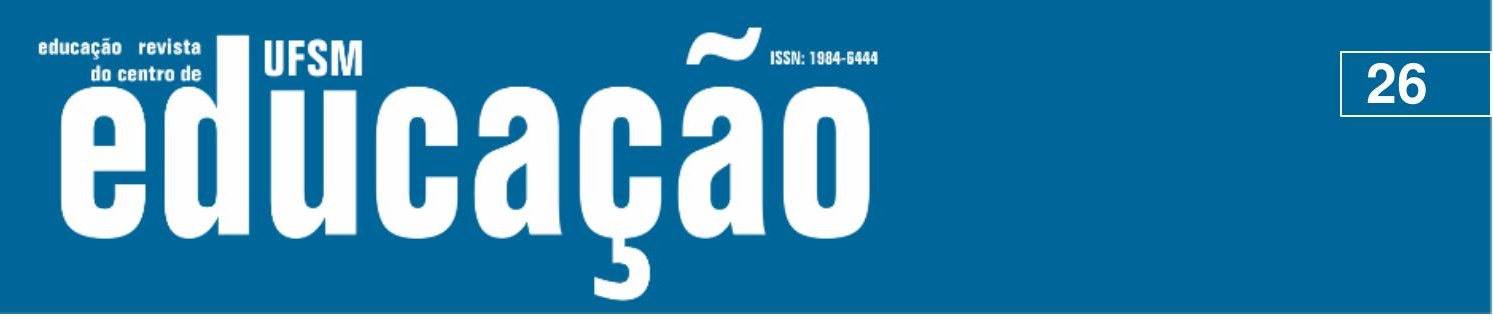

ISSN: 1984-6444 | http://dx.doi.org/10.5902/1984644441141

MUNCINELLI, Sandra Elisa. Libras: língua brasileira de sinais. Revista

Extensão em Foco, Curitiba, v.1, n.1, jun. 2013. Disponível em: http://www.periodicosuniarp.com.br/extensao/article/viewFile/art03/105. Acesso em: 25 jul. 2019.

NOVAES, Beatriz Cavalcanti de Albuquerque Caiuby et al.

Fatores determinantes no desenvolvimento de habilidades comunicativas em crianças com deficiência auditiva

. Jornal da Sociedade Brasileira de Fonoaudiologia, São Paulo, v.24, n.4, 2012. Disponível em: http://www.scielo.br/pdf/jsbf/v24n4/en_a08v24n4.pdf. Acesso em: 21 jul. 2019.

OLIVEIRA, Patrícia Santos; PENNA, Letícia Macedo; LEMOS, Stela Maris Aguiar.

Language development and hearing impairment: literature review. Revista CEFAC,

São Paulo, v.17, n.6, nov/dez. 2015. Disponível em: http://www.scielo.br/pdf/rcefac/v17n6/en_1982-0216-rcefac-17-06-02044.pdf. Acesso em: 20 jul. 2019.

ORGANIZAÇÃO MUNDIAL DA SAÚDE. Grades of hearing impairment. 2014. Disponível em: https://www.who.int/pbd/deafness/hearing_impairment_grades/en/. Acesso em: 30 abr. 2019.

PASSOS, Rosana. Parâmetros Físicos do Movimento em Libras: um estudo sobre intensificadores. Universidade Federal de Minas Gerais, Belo Horizonte, 2014. Disponível em: https://repositorio.ufmg.br/handle/1843/RMSA-ALAGMG. Acess in: 20 jul. 2019.

PIMPERTON, Hannah et al. Language Outcomes in Deaf or Hard of Hearing Teenagers Who Are Spoken Language Users: Effects of Universal Newborn Hearing Screening and Early Confirmation. Ear and Hearing, Filadélfia, v.38, n.5, set. 2017. Disponível em: https://www.ncbi.nlm.nih.gov/pmc/articles/PMC5510717/pdf/aud-38598.pdf. Acesso em: 20 jul. 2019.

PUPIM, Nathalia Ligia Giacomelli et al. A educação física escolar e os alunos surdos. Revista Acta Brasileira do Movimento Humano, Ji-Paraná, v.6, n.2,2016. Disponível

em: http://www.periodicos.ulbra.br/index.php/actabrasileira/article/view/3180. Acesso em: 22 jul. 2019.

SANTOS, Flávia Rodrigues dos; DELGADO-PINHEIRO, Eliane Maria Carrit. Relation among the knowledge of teachers about hearing loss degree, technological devices and communication strategies. CoDAS, São Paulo, v.30, n.6, nov. 2018. Disponível em: http://www.scielo.br/pdf/codas/v30n6/en_2317-1782-codas-30-6-e20180037.pdf. Acesso em: 22 jul. 2019. 


\section{usm

ISSN: 1984-6444 | http://dx.doi.org/10.5902/1984644441141

SENO, Marília Piazzi. A inclusão do aluno com perda auditiva na Rede Municipal de Ensino da cidade de Marília. Revista Psicopedagogia, São Paulo, v.26, n.81, 2009. Disponível em: http://pepsic.bvsalud.org/pdf/psicoped/v26n81/v26n81a05.pdf. Acesso em: 21 jul. 2019.

SILVA, Keli Simões Xavier; OLIVEIRA, Ivone Martins de. The Work of the Brazilian Sign Language Interpreter at School: a case study. Educação \& Realidade, Porto Alegre, v.41, n.3, 2016. Disponível em: http://www.scielo.br/pdf/edreal/v41n3/en_2175-6236-edreal-41-03-00695.pdf. Acesso em: 22 jul. 2019.

TENOR, Ana Claudia; DELIBERATO, Débora. Systematization of a Training Program for Teachers of Deaf Students. Revista Brasileira de Educação Especial, Bauru, v.21, n.3, 2015. Disponível em: http://www.scielo.br/scielo.php?pid=S141365382015000300409\&script=sci_abstract. Acesso em: 22 jul. 2019.

\section{(C) $(1) \Theta$}

This work is licensed under a Creative Commons Attribution-NonCommercial 4.0 International (CC BY-NC 4.0) 